\title{
Metal bioaccumulation and cellular fractionation in an epigeic earthworm (Lumbricus rubellus): the interactive influences of population exposure histories, site-specific geochemistry and mitochondrial genotype
}

Article

Accepted Version

Andre, J., Stürzenbaum, S. R., Kille, P., Morgan, A. J. and Hodson, M. E. (2010) Metal bioaccumulation and cellular fractionation in an epigeic earthworm (Lumbricus rubellus): the interactive influences of population exposure histories, sitespecific geochemistry and mitochondrial genotype. Soil Biology \& Biochemistry, 42 (9). pp. 1566-1573. ISSN 00380717 doi: https://doi.org/10.1016/j.soilbio.2010.05.029 Available at https://centaur.reading.ac.uk/7686/

It is advisable to refer to the publisher's version if you intend to cite from the work. See Guidance on citing.

To link to this article DOI: http://dx.doi.org/10.1016/j.soilbio.2010.05.029

Publisher: Elsevier 
including copyright law. Copyright and IPR is retained by the creators or other copyright holders. Terms and conditions for use of this material are defined in the End User Agreement.

\section{www.reading.ac.uk/centaur}

\section{CentAUR}

Central Archive at the University of Reading

Reading's research outputs online 
1 Metal bioaccumulation and cellular fractionation in an epigeic

2 earthworm (Lumbricus rubellus): the interactive influences of

3 population exposure histories, site-specific geochemistry and 4 mitochondrial genotype.

5

6 Jane Andre ${ }^{\text {ab* }}$, Stephen R. Stürzenbaum ${ }^{c}$, Peter Kille ${ }^{a}$, A. John Morgan ${ }^{\text {a }}$ and 7 Mark E. Hodson'.

8

$9{ }^{a}$ Cardiff School of Biosciences, Cardiff University, Park Place, Cardiff, CF10 3US.

$10{ }^{\mathrm{b}}$ Department of Soil Science, School of Human and Environmental Sciences, University of 11 Reading, Whiteknights, Reading, RG6 6DW.

$12{ }^{\mathrm{c}}$ King's College London, School of Biomedical \& Health Sciences, Department of

13 Biochemistry, Pharmaceutical Sciences Research Division, London, SE1 9NH

$14 *$ Author for correspondence. Current address: Dr. Jane Andre, School of Health and 15 Medicine, Division of Biomedical and Life Sciences, Lancaster University, Lancaster, LA1 $164 \mathrm{YQ}$

17

18

19

20

21

22

23 
25 Subcellular fractionation techniques were used to describe temporal changes (at intervals from $\mathrm{T}_{0}$ to $\mathrm{T}_{70}$ days) in the $\mathrm{Pb}, \mathrm{Zn}$ and $\mathrm{P}$ partitioning profiles of Lumbricus rubellus populations from one calcareous $\left(\mathrm{M}_{\mathrm{DH}}\right)$ and one acidic $\left(\mathrm{M}_{\mathrm{CS}}\right)$ geographically isolated $\mathrm{Pb} / \mathrm{Zn}$-mine sites and one reference site $\left(\mathrm{C}_{\mathrm{PF}}\right) . \mathrm{M}_{\mathrm{DH}}$ and $\mathrm{M}_{\mathrm{CS}}$ individuals were laboratory maintained on their native field soils; $\mathrm{C}_{\mathrm{PF}}$ worms were exposed to both $\mathrm{M}_{\mathrm{DH}}$ and $\mathrm{M}_{\mathrm{CS}}$ soils. Site-specific differences in metal partitioning were found: notably, the putatively metal-adapted populations, $\mathrm{M}_{\mathrm{DH}}$ and $\mathrm{M}_{\mathrm{CS}}$, preferentially partitioned higher proportions of their accumulated tissue metal burdens into insoluble $\mathrm{CaPO}_{4}$-rich organelles compared with naive counterparts, $\mathrm{CPF}_{\mathrm{PF}}$. Thus, it is plausible that efficient metal immobilization is a phenotypic trait characterising metal tolerant ecotypes. Mitochondrial cytochrome oxidase II (COII) genotyping revealed that the populations indigenous to mine and reference soils belong to distinct genetic lineages, differentiated by $\sim 13 \%$, with 7 haplotypes within the reference site lineage but fewer ( 3 and 4, respectively) in the lineage common to the two mine sites. Collectively, these observations raise the possibility that site-related genotype differences could influence the toxico-availability of metals and, thus, represent a potential confounding variable in field-based eco-toxicological assessments.

Keywords: earthworms, $\mathrm{Pb} \& \mathrm{Zn}$, subcellular fractionation, field \& lab exposures, genotyping 
$\underline{\text { Introduction }}$

Direct toxic effects arise in metal-exposed organisms not as a consequence of the total accumulated tissue metal burden per se but when the rate of uptake overtakes the combined rates of excretion and detoxification, such that the internal metal-specific concentration threshold of metabolically-available metal is exceeded (Rainbow, 2007; Pan and Wang, 2008). The threshold concentration denoting the transition from no adverse effect to an observable adverse effect for a given metal is referred to as the critical body residue (CBR) (McCarthy and Mackay, 1993; Péry, et al., 2005). Thus, only a fraction of the body burden is toxicologically (re)active or available (Rainbow, 2002; Vijver, et al., 2004). Organisms have evolved mechanisms to regulate the bioreactivities of essential and non-essential metals (Campbell, et al., 2006). In general these initially entail binding and trafficking by chaperone molecules. Essential cations may subsequently be delivered to physiologically labile intracellular storage sites, classically exemplified by $\mathrm{Ca}^{2+}$-storing endoplasmic reticulum regions, whilst excess essential and non-essential cations can also either be excreted directly or immobilized as insoluble products in specialized organelles often with long half-lives. These structures possess diverse morphologies and matrix compositions (Hopkin, 1989) that are generically referred to as 'metal-rich granules' or 'concretions' (Campbell, et al., 2006).

Improved toxic effects prediction and ecological risk assessment would be likely outcomes of a better knowledge of the fate and speciation of metal within sentinel organisms (Vijver, et al., 2006; Huang, et al., 2009; Jones, et al., 2009). Although there is some evidence from studies on aquatic invertebrates that the toxico-available metals are associated with the cytosolic (soluble) fraction (Perceval, et al., 2006; Péry, et al., 2008), it is generally the case that the relationship between metal induced 
toxicity and accumulated burden is difficult to evaluate due to the cellular compartmentalization of metals (Campbell, et al., 2006; Vijver, et al., 2006). Techniques such as analytical electron microscopy and synchrotron-based X-ray absorption spectroscopy have been used to some extent to characterize the ligandbinding speciation of metals and metalloids in invertebrate tissues (Cotter-Howells, et al., 2005; Langdon, et al., 2005; Arnold, et al., 2008; Andre, et al., 2009). However, a much more widely used method for segregating invertebrate metal burdens into operationally defined detoxified- and non-detoxified subcellular metal compartments is to differentially centrifuge tissue homogenates. To date, such studies have mainly concentrated on aquatic animals (Honeycutt, et al., 1995; Wallace and Lopez, 1997; Conder, et al., 2002; Wallace, et al., 2003; Cain, et al., 2004; Vijver, et al., 2004), but there is a burgeoning body of publications on the assessment of metal partitioning in earthworms (Arnold et al., 2008; Andre et al., 2009; Huang, et al., 2009; Vijver, et al., 2006; Li, et al., 2008; Jones, et al., 2009).

Voets, et al., (2009) reviewed some of the literature demonstrating that the cellular metal distribution patterns in indigenous invertebrate and vertebrate populations often differ from the distribution patterns observed in naive counterpart organisms exposed to metals in laboratory or field-based transplant experiments. Evidently both exposure history and genetic differentiation are biotic variables that can lead to modifications of the efficiency of metal detoxification by invertebrates (Wallace, et al., 2003) as well as vertebrates (Knapen, et al., 2004). Morgan, et al. (2007) also noted that the genetic background of a population can confound biomarker assays, a further indication that the balance between the sensitive and detoxified metal pools can be altered by microevolutionary events. Given that comprehensive phylogenetic studies on earthworms 
using mitochondrial and nuclear markers have recently revealed high intra-species genetic diversity (Velavan, et al., 2007; Novo, et al., 2008) and deeply divergent genetic lineages, possibly in some cases corresponding with cryptic species (King, et al., 2008; Shepeleva, et al., 2008; Pérez-Losada, et al., 2009), it is a major omission that, to the best of our knowledge, no studies hitherto have explicitly attempted to describe the cellular partitioning of metals in field populations of earthworms with respect to exposure history and genotype. A recent report (Langdon, et al., 2009) that populations of the species Lumbricus rubellus inhabiting abandoned arsenic mine sites have evolved resistance to the metalloid brings the omission into sharp focus.

The present study had two main aims. First, to investigate the interactive influences of population exposure history and site-specific geochemistry on subcellular metal $(\mathrm{Pb}$, Zn) and $\mathrm{P}$ partitioning by comparing two putative adapted L. rubellus populations sampled from geochemically contrasting disused $\mathrm{Pb} / \mathrm{Zn}$ mines (one acidic and one calcareous, respectively) and maintained on their native soils with each other and with reference earthworms transferred experimentally to both polluted soils. Phosphorus partitioning was monitored because phosphate is recognised as the predominant counter-ion in earthworm $\mathrm{Pb}$ - and $\mathrm{Zn}$-sequestering cellular compartments (CotterHowells, et al., 2005). The second study aim was to use mitochondrial cytochrome oxidase II (COII) to genotype the three field populations. Andre, et al. (2010) observed site-specific differences in the tissue and subcellular partitioning profiles of L. rubellus populations indigenous to calcareous and acidic sites, respectively. Moreover, the authors reported that the two identified genetically distinct L. rubellus lineages were differentially distributed across a heterogeneous polluted landscape, with lineage ' $\mathrm{A}$ ' predominating within a calcareous $\mathrm{Pb} / \mathrm{Zn}$-polluted 'island' and 
lineage ' $\mathrm{B}$ ' predominating in an adjacent acidic polluted location. The present study extended these previous observations through the novel combination of cell fractionation and genotype analyses applied to geographically isolated populations.

\section{$\underline{\text { Materials and Methods }}$}

\section{$\underline{\text { Soil and earthworm collection and preparation }}$}

Soil and earthworms (mature, L. rubellus) were collected from one control site, Pontcanna Fields ( $\mathrm{C}_{\mathrm{PF}}$ ) ST 165779 (GPS: 51:29.63122N 3:12.24983W) and two contaminated disused, metalliferous mine sites, Draethen Hollow $\left(\mathrm{M}_{\mathrm{DH}}\right)$ ST 217877 (GPS: 51:34.96185N 3:7.88760W) and Cwmystwyth Stream (M $\left.\mathrm{M}_{\mathrm{CS}}\right)$ SN 803748 (GPS: $52: 21.48890 \mathrm{~N} 3: 45.54702 \mathrm{~W})$. At least ten soil samples (excluding the litter layer), taken from a $0-5 \mathrm{~cm}$ depth, were randomly collected from the sampling areas, combined and mixed. The $\mathrm{pH}$ of all soils were measured in deionised $\mathrm{H}_{2} \mathrm{O}$ (Boisson, et al., 1998) prior to them being oven dried at $30^{\circ} \mathrm{C}$ overnight, sieved to $<2 \mathrm{~mm}$, then digested in boiling $16 \mathrm{~N} \mathrm{HNO}_{3}$ (Morgan and Morgan, 1990) and analysed for major inorganic constituents by inductively coupled plasma - optical emission spectroscopy (ICP-OES; Perkin-Elmer Opitma 3000). Analysis of an in house certified reference material (a sewage sludge amended soil) indicated that that the overall analytical error did not exceed $5.2 \%$. In addition the calibration accuracy of the instrument was assessed Comment [MEH1]: Have to include thi as otherwise the reviewer would expect a reference number to see which commercially available CRM was used. If you have the name or number of the CRM you used (normally something like SSXX I can add in the certified composition.

through the analysis of an in-house matrix-matched standard and was within $10 \%$. To provide an indication of the organic matter content, loss on ignition (LOI) was determined for each soil sample. $10 \mathrm{~g}$ (dry weight) of each soil was weighed in a glass crucible and heated to $500^{\circ} \mathrm{C}$ overnight. The percentage weight reduction was then recorded. 


\section{$\underline{\text { Sub-cellular fractionation }}$}

Thirty boxes containing $300 \mathrm{~g}$ of contaminated $\mathrm{M}_{\mathrm{CS}}$ soil and 30 boxes containing $300 \mathrm{~g}$ of contaminated $\mathrm{M}_{\mathrm{DH}}$ soil were established. The soils were wetted to $70 \%$ of their water-holding capacity and reference site $\left(\mathrm{C}_{\mathrm{PF}}\right)$ earthworms were placed into 15 boxes (three individuals per box) of $\mathrm{M}_{\mathrm{CS}}$ and 15 boxes of $\mathrm{M}_{\mathrm{DH}}$ soil. Similarly, 3 native $\mathrm{M}_{\mathrm{DH}}$ earthworms were placed into each of the remaining 15 boxes containing $\mathrm{M}_{\mathrm{DH}}$ soil and 3 native $\mathrm{M}_{\mathrm{CS}}$ earthworms into each of the remaining 15 boxes containing $\mathrm{M}_{\mathrm{CS}}$ soil. At $1,3,14,28$ and 70 days of soil exposure, 3 boxes of each soil-earthworm combination (i.e. maximum ' $n$ ' per 'treatment' $=$ nine) were selected at random and the earthworms depurated prior to freezing. They were depurated for an intial period of 48 hours on moistened filter paper (which was changed daily to prevent coprophagy), followed by 24 hours in a filter-paper free petri-dish (with de-ionised $\mathrm{H}_{2} \mathrm{O}$ ) to allow exudation of any filter paper consumed (Arnold and Hodson, 2007). The total exposure period extended to 10 weeks in order to allow sufficient time for the toxicoavailable fraction to stabilize, as was shown to be the case in the lumbricid species Eisenia fetida with no previous history of metal exposure (Jones et al., 2009). When required the earthworms were defrosted, weighed, homogenized in $0.01 \mathrm{M}$ Tris- $\mathrm{HCl}$, $\mathrm{pH}$ 7.5, and fractionated as described in Arnold, et al., (2008) into a soluble "C fraction" (cytosolic fraction including soluble proteins such as metallothionein and heat shock proteins) and separate insoluble "D" (metal-rich granules) and "E fractions" (tissue fragments, mitochondrial and gut contents) which for the purposes of this study were combined (see supplementary Figure 1). Individual fractions were digested in boiling $16 \mathrm{~N} \mathrm{HNO}_{3}$ (Morgan and Morgan, 1990). Samples were made up to volume with ultra-pure water and analysed for major inorganic constituents by ICPOES with resulting concentrations expressed as $\mathrm{mg}$ of metal per $\mathrm{kg}$ (wet weight) of 
earthworm. Blanks were included for each analyses and detection limits were calculated as $800 \mu \mathrm{g} \mathrm{L} \mathrm{L}^{-1}, 200 \mu \mathrm{g} \mathrm{L} \mathrm{L}^{-1}$ and $400 \mu \mathrm{g} \mathrm{L}^{-1}$ for $\mathrm{P}, \mathrm{Pb}$ and $\mathrm{Zn}$ respectively. No certified reference materials exist for use with this fractionation method but previous analysis of standard additions were within range (10\%), indicating good recovery in the matrix (Arnold et al., 2008) and precision, calculated from repeat analyses of samples was $<5 \%$. Fresh, depurated, weights of the worms sacrificed at each time interval were recorded prior to fractionation; weight change over the exposure periods were taken as estimates of physiological condition.

\section{Mitochondrial Cytochrome Oxidase II (COII) genotyping}

L. rubellus earthworms from the $\mathrm{M}_{\mathrm{DH}}(\mathrm{n}=22), \mathrm{M}_{\mathrm{CS}}(\mathrm{n}=32)$ and $\mathrm{C}_{\mathrm{PF}}(\mathrm{n}=29)$ sites, and single L. castaneus and L. eiseni (from uncontaminated sites in Lancashire, England) were collected by digging and hand-sorting. The animals were transported back to the laboratory in their native soil and depurated (Arnold and Hodson, 2007). A short length (approximately $3 \mathrm{~cm}$ ) of posterior segments was clipped from all L. rubellus individuals, and genomic DNA was extracted using DNAzol reagent (Invitrogen Ltd., Paisley, UK). Forward (5'-TAGCTCACTTAGATGCCA) and reverse (5'GTATGCGGATTTCTAATTGT) L. rubellus-specific primers were used to amplify the cytochrome oxidase II (COII) gene, prior to an Exo-SAP-IT PCR clean-up and sequencing using ABI PRISM ${ }^{\circledR}$ BigDye v3.1 Terminator Sequencing technology (Applied Biosystems, USA) as described by Andre, et al., (2010). Raw sequence traces were confirmed using Finch TV before being imported into Mega v3.1 (Kumar, et al., 2004) for alignment and tree construction. The distance-based neighbour joining (NJ) algorithm (Saitou and Nei, 1987), using p-distance, was used to estimate tree topology and calculate branch lengths. 
Results

\section{$\underline{\text { Soil analysis }}$}

203 Tables 1 and 2 show the concentration of $\mathrm{Pb}, \mathrm{Zn}$ and $\mathrm{P}$ in soil and earthworms sampled from the metalliferous $\mathrm{M}_{\mathrm{CS}}$ and $\mathrm{M}_{\mathrm{DH}}$ and reference $\mathrm{C}_{\mathrm{PF}}$ sites, as well as the percentage body weight change over the full extent of the exposure period. The $\mathrm{Pb}$ and $\mathrm{Zn}$ soil concentrations were highest at the calcareous $\mathrm{M}_{\mathrm{DH}}$ site; acidic $\mathrm{M}_{\mathrm{CS}}$ soil was only mildly contaminated, but contained significantly higher $\mathrm{Pb}$ and $\mathrm{Zn}$ concentrations than the reference $\mathrm{C}_{\mathrm{PF}}$ soil. Phosphorus concentration was significantly higher in $\mathrm{C}_{\mathrm{PF}}$ reference soil than in the two metalliferous soils. $\mathrm{C}_{\mathrm{PF}}$ earthworms maintained higher whole body $\mathrm{P}$ concentrations after 70 days of exposure to both metalliferous soils when compared with their $\mathrm{M}_{\mathrm{DH}}$ and $\mathrm{M}_{\mathrm{CS}}$ counterparts. Mean total earthworm tissue $\mathrm{Pb}$ and $\mathrm{Zn}$ levels to some extent reflected the corresponding soil $\mathrm{Pb}$

213 and $\mathrm{Zn}$ concentrations, although it is noteworthy that the worms indigenous to the

214 acidic $\mathrm{M}_{\mathrm{CS}}$ site had a $\mathrm{Pb}$ bioaccumulation factor of greater than 1 (based upon dry215 weight values, data not shown).

\section{Body mass changes}

218 Mortality was evident across all treatment groups and the mean fresh weights of earthworms, including $\mathrm{C}_{\mathrm{PF}}$ worms on their 'own' unpolluted reference soil, decreased considerably over the exposure period. These observations indicate that a degree of stress mediated by dietary restriction and/or metal toxicity was experienced by all earthworms in our experimental regime. 
Lead: Following a ten-week exposure period, the ex-situ partitioning profiles were similar for both indigenous and naive introduced earthworms exposed to the same soil (Figure 1). Significant increases in $\mathrm{Pb}$ concentration were seen in the soluble (C) and insoluble (D+E) fractions of all worms exposed to $\mathrm{M}_{\mathrm{DH}}$ soil, and $\mathrm{C}_{\mathrm{PF}}$ individuals exposed to $\mathrm{M}_{\mathrm{CS}}$ soil. $\mathrm{M}_{\mathrm{CS}}$ individuals only demonstrated a slight increase in insoluble $\mathrm{Pb}$. Destroying the physical integrity of the field soils by indiscriminate sampling, drying, sieving, homogenisation, and re-hydrating appears to have released more metal for uptake into earthworm tissues above the corresponding equilibrated field levels. $\mathrm{Pb}$ was found to preferentially partition into the non-soluble or detoxified (D+E) fraction in all earthworm/soil combinations (Figure 1B). Plotting the time course partitioning data with the soluble fraction $\mathrm{Pb}$ values expressed as a percentage of the whole body $\mathrm{Pb}$ concentration values (Figure 2) revealed differences in the efficiencies of incorporating $\mathrm{Pb}$ into the detoxified fraction between indigenous worms and naive worms introduced into the metalliferous soils. Specifically, and consistently over the entire exposure period, the proportion of $\mathrm{Pb}$ within the sensitive soluble fraction of $\mathrm{M}_{\mathrm{CS}}$ earthworms was proportionately less than that in $\mathrm{C}_{\mathrm{PF}}$ earthworms maintained on $\mathrm{M}_{\mathrm{CS}}$ soil (Figure 2A). A similar efficiency difference was

242 found between $\mathrm{M}_{\mathrm{DH}}$ and $\mathrm{C}_{\mathrm{PF}}$ earthworms, but only after 10-weeks of exposure (Figure 2B); at earlier intervals no difference was apparent in $\mathrm{Pb}$ partitioning between these two populations. Naïve earthworms accumulated $\mathrm{Pb}$ linearly in all three fractions over the duration of the exposure period. In contrast, after 28 days $\mathrm{M}_{\mathrm{DH}}$ earthworms preferentially partitioned the majority of accumulated metal into the insoluble (detoxified) fraction. As the concentrations of $\mathrm{Cu}, \mathrm{Ni}$, and $\mathrm{Sr}$ did not change appreciably over the 10 week exposure period (data not shown), this implies that the 
temporal changes in the concentrations of $\mathrm{Pb}$ and $\mathrm{Zn}$ in the subcellular fractions were not directly linked to the loss of whole-worm weight over this period.

252 Zinc: The temporal partitioning profiles of $\mathrm{Zn}$ resemble those of $\mathrm{Pb}$, with indigenous worms with multi-generational histories of metal exposure $\left(\mathrm{M}_{\mathrm{DH}}\right.$ and $\left.\mathrm{M}_{\mathrm{CS}}\right)$ and naive worms with no previous field history of exposure $\left(\mathrm{C}_{\mathrm{PF}}\right)$ each sequestering $\mathrm{Zn}$ primarily in the insoluble (D+E) fraction, and restricting the cytosolic soluble $\mathrm{Zn}$ fraction within relatively narrow limits (Figure 3). Zn uptake in both the soluble and insoluble fractions by naive $\mathrm{C}_{\mathrm{PF}}$ earthworms exposed to $\mathrm{M}_{\mathrm{DH}}$ soil occurred in a linear fashion during the entire exposure period, whereas after 28 days of exposure $\mathrm{M}_{\mathrm{DH}}$ earthworms appeared to preferentially partition $\mathrm{Zn}$ into the insoluble (detoxified) fraction. The similarities between $\mathrm{Pb}$ and $\mathrm{Zn}$ partitioning extended to the comparative efficiency of restricting the metals to the detoxified compartment in indigenous versus introduced populations (Figure 4): the proportion of Zn present in the soluble fraction was appreciably lower in earthworms from the heavily polluted $\mathrm{M}_{\mathrm{DH}}$ site at all time points compared with that in $\mathrm{C}_{\mathrm{PF}}$ worms introduced to the $\mathrm{M}_{\mathrm{DH}}$ soil; the proportion of soluble fraction $\mathrm{Zn}$ in $\mathrm{M}_{\mathrm{CS}}$ worms was appreciably lower than in $\mathrm{C}_{\mathrm{PF}}$ worms maintained on $\mathrm{M}_{\mathrm{CS}}$ soil at three time points (3, 14, and 70 days).

Phosphorus: In both indigenous mine-site populations maintained on their 'own' soils, and in naive worms introduced to the metalliferous soils, a fairly steady redistribution of $\mathrm{P}$ from the soluble cytosolic phase to the insoluble compartment occurred during the ten-week exposure period (cf. Figures 5A and 5B). A considerably higher insoluble $\mathrm{P}$ concentration was measured in indigenous and 
introduced earthworms exposed to $\mathrm{M}_{\mathrm{DH}}$ soil compared with the two treatment groups exposed to the significantly less polluted $\mathrm{M}_{\mathrm{CS}}$ soil (Figure 5).

\section{Cytochrome oxidase II (COII) genotyping}

The phylogenetic structure of the study populations was assessed using the mitochondrial cytochrome oxidase II (mtDNA COII) gene sequence data of individuals sampled from the three sites. Good quality COII nucleotide sequences (304bp) were aligned from 85 L. rubellus earthworms and from individuals of $L$. castaneus and L. eiseni to rule out the possibility of misidentification. Only functional COII sequences, with no stop or nonsense codons in the reading frame, were used. Intra- and inter-site evolutionary relationships were phylogenetically analysed (Figure 6), with the tree constructed using the distance-based neighbour joining (NJ) algorithm based upon p-distance. Only one representative of each site and haplotype are shown and the resulting tree topology was well supported by bootstrap analyses. The sampled L. rubellus individuals could be resolved into two distinct genetic lineages (lineage A and B, respectively), with a mean inter-lineage mtDNA sequence divergence of $13 \%$.

$\mathrm{C}_{\mathrm{PF}}$ earthworms grouped exclusively within lineage $\mathrm{A}$, and comprised 7 distinct haplotypes, with a between-haplotype diversity of 1 to $4 \%$ (Figure 6). In comparison, the $\mathrm{M}_{\mathrm{DH}}$ and $\mathrm{M}_{\mathrm{CS}}$ populations derived from mine-associated soils belonged predominantly to the lineage $\mathrm{B}$ genotype, and comprised $3\left(\mathrm{M}_{\mathrm{DH}}\right)$ and 4 haplotypes

$295\left(\mathrm{M}_{\mathrm{CS}}\right)$ exhibiting between-haplotype diversity of 1 to $2 \%$, respectively. Only one individual from each mine site had lineage A genotype signatures. The genetic distance between $L$. rubellus and two other Lumbricus species ( $L$. castaneus and $L$. 
eiseni) was calculated as $18.1 \%$, thus indicating that the $L$. rubellus field populations were correctly assigned.

\section{$\underline{\text { Discussion }}$}

Abandoned metal mine soils in the UK and elsewhere harbour locally adapted earthworm populations with innate abilities to tolerate phenomenally high internal body loads of certain metals. For example, earthworms evidently thrive in field soils contaminated to degrees exceeding by an order of magnitude the exposure level that severely compromises reproduction in spiked laboratory soils (Spurgeon, et al., 1994). That these are residents and not immigrants from less-contaminated surrounding soil is one way of interpreting the 'patchy' pattern of genotype distributions observed in $L$. rubellus across geochemically heterogeneous metalliferous landscapes (Andre, et al., 2010). A number of published studies provide mechanistic insights concerning the modes of metal detoxification within discrete subcellular compartments in these chronically exposed natural populations (Morgan and Morris, 1982; Morris and

313 Morgan, 1986; Morgan and Morgan, 1989a; 1998; Sturzenbaum, et al., 2001).

314 However, evidence of phenotypic differences at the behavioural, physiological and 315 molecular levels between populations that have undergone multiple generations of exposure and their counterparts with no comparable metal exposure history in their native habitat remain sparse. Therefore, by comparing the subcellular partitioning profiles amongst earthworm populations native to contaminated and clean sites, further inferences into the metal management strategies of putatively adapted ecotypes may be gained. 
A Cd-resistant ecotype of the freshwater oligochaete Lumbriculus hoffmeisteri has been shown to possess enhanced $\mathrm{Cd}$ accumulation efficiency (Klerks and Bartholomew, 1991) and a concomitant reduction in the amount of trophicallyavailable Cd (Wallace and Lopez, 1997). Such integrated duality is also expressed for $\mathrm{Pb}$ in at least one of the earthworm populations, $\mathrm{M}_{\mathrm{DH}}$, examined in the present study. Specifically, $\mathrm{Pb}$ partitioning profiles for $\mathrm{M}_{\mathrm{DH}}$ individuals showed a much lower absolute level of soluble $\mathrm{Pb}$ (approximately 57\% after 70 days exposure), when compared to naive $C_{P F}$ earthworms exposed to the same $M_{D H}$ polluted soil. This population appears to have evolved a capability to limit $\mathrm{Pb}$ toxico-availability possibly through modifications of components of $\mathrm{Ca}^{2+}$ transporting pathway, such as 332 the sarcoplasmic/endoplasmic reticulum calcium ATPase (SERCA) (Andre, et al., 2010). The notion is supported by plotting the soluble $\mathrm{Pb}$ fraction of $\mathrm{M}_{\mathrm{DH}}$ worms as a percentage of the total body load; although the total body burden increases over the 10 week exposure period on their native soil, there is a significantly lower proportion of the $\mathrm{Pb}$ burden distributed in the soluble fraction compared with that found in $\mathrm{C}_{\mathrm{PF}}$ reference site worms maintained in the laboratory for the same period on $\mathrm{M}_{\mathrm{DH}}$ metalliferous soil. A similar differential was also recorded in the proportional $\mathrm{Pb}$ content of the soluble fractions of $\mathrm{M}_{\mathrm{CS}}$ and $\mathrm{C}_{\mathrm{PF}}$ worms at all time intervals of laboratory exposure to $\mathrm{M}_{\mathrm{CS}}$ soil. This phenomenon of increasing metal concentrations in earthworms from metal-contaminated soils maintained on their 'own' soils in the laboratory has been reported by others (e.g. Corp and Morgan, 1991). It is not easily explained in the cases of metal that are not especially redox active other than as a 344 consequence of the destruction of the physical structure of soil, with a release of previously stabilized metal into the 'bioavailable' pool, i.e. a partial reversal of the 346 'ageing' process. The indication that $\mathrm{Pb}$ bioreactivity is reduced in earthworms 
indigenous to $\mathrm{Pb}$-contaminated soils was reinforced by the finding that the weight loss experienced by reference $\mathrm{C}_{\mathrm{PF}}$ earthworms maintained on the two studied metalliferous soils exceeded that experienced by earthworms native to the field soils. These data highlight the crucial role that intracellular components and machinery play in facilitating the efficient delivery of metals to intracellular compartments where they are sequestered in insoluble states.

Several publications have shown that lysosome-like chloragosomes within the chlorogogenous tissue (possessing some functional similarities to vertebrate hepatocytes) are the main metal-sequestering organelles. Chloragosomes represent phosphate-rich storage compartments for group A, O-seeking, metals (Morgan and Morris, 1982; Morgan and Morgan, 1989a; b; 1998). Andre, et al., (2009) investigated the ligand speciation of $\mathrm{Pb}$ within whole earthworms using synchrotron- based XAS analysis, and obtained XANES spectra that unambiguously revealed that L. rubellus with a protracted population history of $\mathrm{Pb}$ exposure preferentially sequester the metal as insoluble pyromorphite $\left[\mathrm{Pb}_{5}\left(\mathrm{PO}_{4}\right)_{3} \mathrm{Cl}\right]$ and $\mathrm{Pb}_{3}\left(\mathrm{PO}_{4}\right)_{2}$. Given this fact, the observation in the present study that intracellular P speciation shifts appreciably in all exposures over the entire 10 week period from a relatively soluble to less soluble state presumably to associate with intruding $\mathrm{Pb}$ is functionally logical.

Due to its biological essentiality it is predictable that invertebrates are able to regulate intracellular $\mathrm{Zn}$ levels to a considerable degree. Chromatographic observations demonstrate that this may be achieved through $\mathrm{Zn}$ binding to a variety of low- and high-molecular weight molecules (Susuki, et al., 1988; Cain and Luoma, 1998; Lock 
and Janssen, 2001). Homeostatic systems operate to not only sequester and detoxify excess $\mathrm{Zn}$ but, when needed, to release $\mathrm{Zn}$ in order to meet the cells physiological requirements. This system is undoubtedly at work in earthworms from $\mathrm{M}_{\mathrm{DH}}$ as, despite considerable increases in total body load, they demonstrate the ability to maintain their intracellular soluble $\mathrm{Zn}$ content within relatively narrow limits. Again, the phosphate-rich chloragosomes are implicated in $\mathrm{Zn}$ storage and detoxification alongside a less well characterised sulphur-rich organelle, the cadmosome (Sturzenbaum, et al., 1998). The involvement of chloragosomes and cadmosomes in excess $\mathrm{Zn}$ sequestration has been corroborated by XAS analyses, with XANES spectra indicating that $\mathrm{Zn}$ binds to both $\mathrm{O}$ - and S-donating ligands (Andre, et al., 2009).

Cryptic or sibling species are typically found in taxa that thrive in complex, heterogeneous, environments and have been discovered by genotyping fauna inhabiting diverse marine, freshwater, and terrestrial habitats (Sturmbauer, et al., 1999; Pinceel, et al., 2004; Mathews, 2006; Pfenninger and Schwenk, 2007). The L. rubellus population indigenous to the unpolluted field site, $\mathrm{C}_{\mathrm{PF}}$, belongs exclusively to lineage $\mathrm{A}$ and can be resolved into 7 haplotypes, whilst the two geographically isolated mine-site populations both belong to the genotypically distinct lineage B comprised of 3 and 4, respectively, distinct haplotypes. The number of L. rubellus populations examined was too restricted to draw firm conclusions regarding microevolutionary genealogies, but the higher intra-lineage diversity of the $\mathrm{C}_{\mathrm{PF}}$ sample is indicative of a relatively stationary population that has undergone multiple introductions and bottleneck episodes during its evolutionary history (Harpending, 1994). It is tempting to interpret the comparatively narrow genetic diversity within the 
lineage B inhabitants of the mine sites as a hallmark of stress-driven genetic erosion processes (natural selection, genetic drift, inbreeding) having acted upon these populations. Genetic erosion can certainly accompany small fragmented populations (Buza et al., 2000) such as those found inhabiting the 'islands of toxicity' that typify abandoned metal mine sites. However, the genetic erosion notion as an explanation of the genetic structure of mine-associated earthworm populations should be tempered with the knowledge that calculations from genetic parameters lead to the conclusion that lineage A (with an inter-stadial expansion time of $\sim 250000$ years BP) is appreciably 'older' than lineage B (expansion time of 17000 years BP) (Andre, et al., 2010) and may have had the opportunity to evolve more genetic richness. Peles, et al. (2003) suggested that certain alleles and genotypes in L. rubellus may be more sensitive to the effects of heavy metals because the frequency of both differed significantly at polymorphic loci between populations inhabiting sewage contaminated and reference soils. Conversely, Haimi, et al. (2007) reported that metal contamination did not significantly impact upon clonal diversity in the earthworm Dendrobaena octaedra. Analogous inter- or intra-lineage conclusions cannot firmly be drawn from the present study on L. rubellus. Whether or not the two deeply divergent L. rubellus lineages warrant the status of (cryptic) species must await further genetic and breeding evidence. Nevertheless, it is noteworthy that Lentzsch and Golldack (2006) observed that species richness not ambient soil conditions was the overriding factor affecting intraspecific diversity and genotype abundance in the earthworm Aporrectodea caliginosa, thus ostensibly supporting the hypothesis that ecological niches are colonised at a species level prior to local population-level adaption. The shallow soils often associated with abandoned metal mines usually 
harbour impoverished earthworm communities, in many instances no more than two taxonomically accepted representatives of the epigeic ecophysiological group.

In conclusion, the ability of an adapted population to tolerate the prevailing stressevoking conditions in severely polluted habitats most probably involve heritable and integrated combinations of physiological, morphological and behavioural modifications. Thus, it is plausible to hypothesise that a metal tolerant earthworm population has evolved efficient mechanisms of detoxification that feature an enhanced immobilisation capacity coupled to a relative reduction in the metal sensitive fraction as an important component of their holistic adaptive arsenal. However, inferences about population-specific adaptation based on subcellular metal partitioning profiles should be drawn with a measure of caution because of the possibility that they could be attributable to lineage-specific traits that are independent of chronic metal exposure. This is illustrated by the findings of (Heethoff, et al., 2004) that the parthenogenic earthworm Octolasion tyrtaeum is differentiated into two lineages differing significantly in body size. Such findings, together with those arising from the present study, raise the spectre that field-based eco-toxicological assessments that utilise earthworms, particularly those emanating from discriminating 'omics' measurements, might benefit from the elimination of a potential confounding biotic variable through prior genotyping of all individuals to establish that they possess some genetic background equivalence.

442 Acknowledgments. This work was performed during the tenure of a Natural Environment Research Council studentship (JA) registered at Reading University, and 444 a research grant (F0 0407/AI) awarded by The Leverhulme Trust to AJM. We thank 
Dr Trevor Piearce of Lancaster University for providing us with specimens of Lumbricus eiseni for genotyping.

\section{$\underline{\text { References }}$}

Andre, J., Charnock, J., Stürzenbaum, S.R., Kille, P., Morgan, A.J., Hodson, M.E.,

2009. Accumulated Metal Speciation in Earthworm Populations with

Multigenerational Exposure to Metalliferous Soils: Cell Fractionation and High6829.

Andre, J., King, R.A., Stürzenbaum, S.R., Kille, P., Hodson, M.E., Morgan, A.J., 2010. Molecular genetic differentiation in earthworms inhabiting a heterogeneous $\mathrm{Pb}$ polluted landscape. Environmental Pollution 158, 883-890.

Arnold, R.E., Hodson, M.E., 2007. Effect of time and mode of depuration on tissue copper concentrations of the earthworms Eisenia andrei, Lumbricus rubellus and Lumbricus terrestris. Environmental Pollution 148, 21-30.

Arnold, R.E., Hodson, M.E., Charnock, J.M., Peijnenburg, W.J.G.M., 2008. Comparison of the subcellular partitioning, distribution and internal speciation of $\mathrm{Cu}$ between $\mathrm{Cu}$-tolerant and naive populations of Dendrodrilus rubidus Savigny. Environmental Science and Technology 42, 3900-3905. term in situ immobilization of $\mathrm{Cd}$ and $\mathrm{Ni}$ by beringite and steel shots application to long-term sludged plots. Agronomie 18, 347-359. 
Buza, L., Young, A., Thrall, P. (2000). Genetic erosion, inbreeding and reduced fitness in fragmented populations of the endangered tetraploid pea Swainsona recta. Biological Conservation 93, 177-186.

Cain, D.J., Luoma, S.N., 1998. Metal exposures to native populations of the caddisfly Hydropsyche (Trichoptera: Hydropsychidae) determined from cytosolic and whole body metal concentrations. Hydrobiologia 386, 103-117.

Cain, D.J., Luoma, S.N., Wallace, W.G., 2004. Linking metal bioaccumulation of aquatic insects to their distribution patterns in a mining- impacted river. Environmental Toxicology and Chemistry 23, 1463-1473.

Campbell, P.G.C., Chapman, P.M., Hale, B.A., 2006. Risk assessment of metals in the environment. Issues in Environmental Science and Technology 22, 101-131.

Conder, J.M., Seals, L.D., Lanno, R.P., 2002. Method for determining toxicologically relevant cadmium residues in the earthworm Eisenia fetida. Chemosphere 49, 1-7.

Corp, N., Morgan, AJ., 1991. Accumulation of heavy metals from polluted soils by the earthworm Lumbricus rubellus: Can laboratory exposure of 'control' worms reduce biomonitoring problems? Environmental Pollution 74, 39-52 2005. Metal Compartmentation and Speciation in a Soil Sentinel: The Earthworm, Dendrodrilus rubidus. Environmental Science and Technology 39, 7731-7740.

Haimi, J., Knott, K.E., Yliniemi, I., 2007. Does metal contamination affect clonal diversity of the parthenogenetic earthworm Dendrobaena octaedra? European Journal 
Harpending, H.C., 1994. Signature of Ancient Population-Growth in a LowResolution Mitochondrial-DNA Mismatch Distribution. Human Biology 66, 591-600.

Heethoff, M., Etzold, K., Scheu, S., 2004. Mitochondrial COII sequences indicate that the parthenogenetic earthworm Octolasion tyrtaeum (Savigny 1826) constitutes of two lineages differing in body size and genotype. Pedobiologia 48, 9-13.

Honeycutt, M.E., Roberts, B.L., Roane, D.S., 1995. Cadmium deposition in the earthworm Eisenia fetida. Ecotoxicology and Environmental Safety 30, 143-150.

Hopkin, S.P., 1989. Ecophysiology of metals in terrestrial invertebrates. Elsevier Applied Science, Barking, UK.

Huang, R., Wen, B., Pei, Z., Shan, X.Q., Zhang, S., Williams, P.N., 2009. Accumulation, Subcellular Distribution and Toxicity of Copper in Earthworm (Eisenia fetida) in the Presence of Ciprofloxacin. Environmental Science and Technology 43, 3688-3693.

Jones, R.P., Bednar, A.J., Inouye, L.S., 2009. Subcellular compartmentalization of lead in the earthworm, Eisenia fetida: Relationship to survival and reproduction. Ecotoxicology and Environmental Safety 72, 1045-1052.

King, R.A., Tibble, A., Symondson, W.O.C., 2008. Opening a can of worms: unprecedented sympatric cryptic diversity within British lumbricid earthworms. Molecular Ecology 17, 4684-4698.

Klerks, P.L., Bartholomew, P.R., 1991. Cadmium accumulation and detoxification in a Cd-resistant population of the oligochaete Limnodrilus hoffmeisteri. Aquatic Toxicology 19, 97-112 
511 Knapen, D., Bervoets, L., Verheyen, E., Blust, R., 2004. Resistance to water pollution

512 in natural gudgeon (Gobio gobio) populations may be due to genetic adaptation.

513 Aquatic Toxicology 67, 155-165.

514 Kumar, S., Tamura, K., Nei, M., 2004. MEGA3: Integrated software for Molecular

515 Evolutionary Genetics Analysis and sequence alignment. Briefings in Bioinformatics

$5165,150-163$.

517 Langdon, C.J., Hodson, M.E., Arnold, R.E., Black, S., 2005. Survival, Pb-uptake and 518 behaviour of three species of earthworm in $\mathrm{Pb}$ treated soils determined using an 519 OECD-style toxicity test and a soil avoidance test. Environmental Pollution 138.

Langdon, C.J., Morgan, A.J., Charnock, J.M., Semple, K.T., Lowe, C.N., 2009. Asresistance in laboratory-reared F1, F2 and F3 generation offspring of the earthworm Lumbricus rubellus inhabiting an As-contaminated mine soil. Environmental Pollution 157, 3114-3119.

Lentzsch, P., Golldack, J., 2006. Genetic diversity of Aporrectodea caliginosa from agricultural sites in Northeast Brandenburg, Germany. Pedobiologia 50, 369-376.

Li, L.Z., Zhou, D.M., Wang, P., Luo, X.S., 2008. Subcellular distribution of Cd and $\mathrm{Pb}$ in earthworm Eisenia fetida as affected by $\mathrm{Ca}^{2+}$ ions and $\mathrm{Cd}-\mathrm{Pb}$ interaction. Ecotoxicology and Environmental Safety 71, 632-637.

Lock, K., Janssen, C.R., 2001. Zinc and cadmium body burdens in terrestrial oligochaetes: Use and sigificance in environmental risk assessment. Environmental

531 Toxicology and Chemistry 20, 2067-2072. 
Mathews, L.M., 2006. Cryptic biodiversity and phylogeographical patterns in a snapping shrimp species complex. Molecular Ecology 15, 4049-4063.

534 McCarthy, L.S., Mackay, D., 1993. Enhancing ecotoxicological moedeling and assessment. Environmental Science and Technology 27, 1719-1728.

Morgan, A.J., Kille, P., Sturzenbaum, S.R., 2007. Microevolution and ecotoxicology of metals in invertebrates. Environmental Science and Technology 41, 1085-1096.

Morgan, A.J., Morris, B., 1982. The accumulation and intracellular compartmentation of cadmium, lead, zinc and calcium in two earthworm species (Dendrobaena rubida and Lumbricus rubellus) living in highly contaminated soil. Histochemistry and Cell Biology 75, 269-285.

542 Morgan, J.E., Morgan, A.J., 1989a. The effect of lead incorporation on the elemental composition of earthworm (Annelida, Oligochaeta) chloragosome granules. Histochemistry 92, 237-241.

Morgan, J.E., Morgan, A.J., 1989b. Zinc sequestration by earthworm (Annelida: Oligochaeta) chloragocytes. Histochemistry and Cell Biology 90, 405-411.

547 Morgan, J.E., Morgan, A.J., 1990. The distribution of cadmium, copper, lead, zinc 548 and calcium in the tissues of the earthworm Lumbricus rubellus sampled from one 549 uncontaminated and four polluted soils. Oecologia 84, 559-566.

550 Morgan, J.E., Morgan, A.J., 1998. The distribution and intracellular compartmentalisation of metals in the endogeic earthworm Aporrectodea caliginosa sampled from an unpolluted and a metal contaminated site. Environmental Pollution 99, 167-175. 
Morris, B., Morgan, A.J., 1986. Calcium-lead interactions in earthworms: Observations on Lumbricus terrestris sampled from a calcareous abandoned lead mine site. Bulletin of Environmental Contamination and Toxicology 37, 226-233.

Novo, M., Velavan, T.P., AlmodOvar, A., Schulenburg, H., Diaz-CosIn, D.J.,

558 Michiels, N.K., 2008. Microsatellite markers for the drought-resistant earthworm Hormogaster elisae. Molecular Ecology Resources 8, 901-903.

Pan, K., Wang, W.X., 2008. The subcellular fate of cadmium and zinc in the scallop Chlamys nobilis during waterborne and dietary metal exposure. Aquatic Toxicology 90, 253-260.

Peles, J.D., Towler, W.I., Guttman, S.I., 2003. Population genetic structure of earthworms (Lumbricus rubellus) in soils contaminated by heavy metals. Ecotoxicology 12, 379-386.

Perceval, O., Couillard, Y., Pinel-Alloul, B., Campbell, P.G.C., 2006. Linking changes in subcellular cadmium distribution to growth and mortality rates in transplanted freshwater bivalves (Pyganodon grandis). Aquatic Toxicology 79, 87-98.

Pérez-Losada, M., Ricoy, M., Marshall, J.C., Domínguez, J., 2009. Phylogenetic assessment of the earthworm Aporrectodea caliginosa species complex (Oligochaeta: Lumbricidae) based on mitochondrial and nuclear DNA sequences. Molecular Phylogenetics and Evolution 52, 293-302.

Péry, A.R.R., Béthune, A., Gahou, J., Mons, R., Garric, J., 2005. Body residues: a key variable to analyze toxicity tests with Chironomus riparius exposed to copper-spiked sediments. Ecotoxicology and Environmental Safety 61, 160-167. 

of metal mixtures in contaminated sediments on Chironomus riparius based on cytosolic accumulation. Ecotoxicology and Environmental Safety 71, 869-873.

Pfenninger, M., Schwenk, K., 2007. Cryptic animal species are homogeneously distributed among taxa and biogeographical regions. BMC Evolutionary Biology 7, 121.

Pinceel, J., Jordaens, K., Van Houtte, N., De Winter, A.J., Backeljau, T., 2004. Molecular and morphological data reveal cryptic taxonomic diversity in the terrestrial slug complex Arion subfuscus/fuscus (Mollusca, Pulmonata, Arionidae) in continental north-west Europe. Biological Journal of the Linnean Society 83, 23-38.

Rainbow, P.S., 2002. Trace metal concentrations in aquatic invertebrates: why and so what? Environmental Pollution 120, 497-507.

Rainbow, P.S., 2007. Trace metal bioaccumulation: Models, metabolic availability and toxicity. Environment International 33, 576-582.

Saitou, N., Nei, M., 1987. The Neighbor-Joining Method - a New Method for Reconstructing Phylogenetic Trees. Molecular Biology and Evolution 4, 406-425.

Shepeleva, O.A., Kodolova, O.P., Zhukovskaya, E.A., Striganova, B.R., 2008.

593 Genetic diversity of populations of the earthworm Lumbricus rubellus (Hoffm.)(Oligochaeta, Lumbricidae). Biology Bulletin 35, 170-177.

Spurgeon, D.J., Hopkin, S.P., Jones, D.T., 1994. Effects of cadmium, copper, lead and 
Assessing the environmental impact of point-source metal contamination in terrestrial ecosystems. Environmental Pollution 84, 123-130.

Sturmbauer, C., Opadiya, G.B., Niederstatter, H., Riedmann, A., Dallinger, R., 1999. Mitochondrial DNA reveals cryptic oligochaete species differing in cadmium resistance. Molecular Biology and Evolution 16, 967-974.

Sturzenbaum, S.R., Kille, P., Morgan, A.J., 1998. The identification, cloning and characterisation of earthworm metallothionein. FEBS Letters 431, 437-442.

Sturzenbaum, S.R., Winters, C., Galay, M., Morgan, A.J., Kille, P., 2001. Metal ion trafficking in earthworms. Identification of a cadmiun-specific metallothionein. The Journal of Biological Chemistry 276, 34013-34018.

Susuki, K.T., Sunaga, H., Aoki, Y., Hatakeyama, S., Sugaya, Y., Sumi, Y., Suzuki, T., 1988. Binding of cadmium and copper in the matfly Baetis Thermicus that inhabit 609 a river polluted with heavy metals. Comparative Biochemistry and Physiology C Comparative Pharmacology 91C, 487-492.

611 Velavan, T.P., Schulenburg, H., Michiels, N., 2007. Development and 612 characterization of novel microsatellite markers for the common earthworm 613 (Lumbricus terrestris L.). Host-Parasite Interactions 7, 24.

614 Vijver, M.G., Van Gestel, C.A.M., Lanno, R.P., Van Straalen, N.M., Peijnenburg, 615 W.J.G.M., 2004. Internal metal sequestration and its ecotoxicological relevance: a 616 review. Environmental Science and Technology. 38, 4705-4712.

617 Vijver, M.G., van Gestel, C.A.M., van Straalen, N.M., Lanno, R.P., Peijnenburg, 618 W.J.G.M., 2006. Biological significance of metals partitioned to subcellular fractions 

Chemistry 25, 807-814.

621 Voets, J., Redeker, E.S., Blust, R., Bervoets, L., 2009. Differences in metal sequestration between zebra mussels from clean and polluted field locations. Aquatic Toxicology 93, 53-60.

Wallace, W.G., Lee, B.G., Luoma, S.N., 2003. Subcellular compartmentalistion of Cd and $\mathrm{Zn}$ in two bivalves. 1. Significance of metal-sensitive fractions (MSF) and biologically detoxified metal (BDM). Marine Ecology Progress Series 249, 183-197.

Wallace, W.G., Lopez, G.R., 1997. Bioavailability of biologically sequestered 628 cadmium and the implications of metal detoxification. Marine Ecology Progress Series 1997, 149-157.

\section{$\underline{\text { Figure Legends }}$}

632 Figure 1

633 Time course of $\mathrm{Pb}$ partitioning into soluble (A) and non-soluble (B) cellular fractions

634 in Lumbricus rubellus sampled from three populations and maintained on two mine635 associated metal contaminated soils. $\mathrm{Pb}$ concentrations (per unit wet weight of earthworm) are presented as mean \pm S.E. (maximum ' $n$ ' $=9$ ). $C_{P F}$ refers to the reference site at Pontcanna Fields, $\mathrm{M}_{\mathrm{CS}}$ the metalliferous acidic site Cwmystwyth Stream and $\mathrm{M}_{\mathrm{DH}}$ the metalliferous calcareous site, Draethen Hollow.

$640 \quad$ Figure 2

641 Time course of subcellular $\mathrm{Pb}$ distribution in Lumbricus rubellus sampled from three 642 populations and maintained on two mine-associated metal contaminated soils, with 

concentration. The $\mathrm{Pb}$ levels shown represent fractions extracted from $\mathrm{M}_{\mathrm{CS}}$ and $\mathrm{C}_{\mathrm{PF}}$ earthworms in $\mathrm{M}_{\mathrm{CS}}$ soil (A) and $\mathrm{M}_{\mathrm{DH}}$ and $\mathrm{C}_{\mathrm{PF}}$ earthworms in $\mathrm{M}_{\mathrm{DH}}$ soil (B). [See Fig.

6461 for dataset error bars and Fig. 1 legend for site identifiers.]

648 Figure 3

649 Time course of $\mathrm{Zn}$ partitioning into soluble (A) and non-soluble (B) cellular fractions 650 in Lumbricus rubellus sampled from three populations and maintained on two mine651 associated metal contaminated soils. Zn concentrations (per unit wet weight of earthworm) are presented as mean \pm S.E. (maximum 'n' =9). [See Fig. 1 legend for 653 site identifiers.]

Figure 4

Time course of subcellular $\mathrm{Zn}$ distribution in Lumbricus rubellus sampled from three populations and maintained on two field mine-associated metal contaminated soils,

658 with the soluble metal concentration expressed as a percentage of the total body concentration. The $\mathrm{Zn}$ levels shown represent fractions extracted from $\mathrm{M}_{\mathrm{CS}}$ and $\mathrm{C}_{\mathrm{PF}}$

660 earthworms in $\mathrm{M}_{\mathrm{CS}}$ soil (A) and $\mathrm{M}_{\mathrm{DH}}$ and $\mathrm{C}_{\mathrm{PF}}$ earthworms in $\mathrm{M}_{\mathrm{DH}}$ soil (B). [See Fig. 1

661 for dataset error bars and Fig. 1 legend for site identifiers.]

662

Figure 5

664 Time course of $\mathrm{P}$ partitioning into soluble (A) and non-soluble (B) cellular fractions in 665 Lumbricus rubellus sampled from three populations and maintained on two fieldderived metal contaminated soils. $\mathrm{P}$ concentrations (per unit wet weight of 
$670 \quad$ Figure 6

671 Phylogenetic tree based on p-distance of the cytochrome oxidase II mitochondrial 672 gene of 87 Lumbricus rubellus individuals from the contaminated sites $\mathrm{M}_{\mathrm{DH}}$ 673 (triangles) and $\mathrm{M}_{\mathrm{CS}}$ (circles) and the reference site $\mathrm{C}_{\mathrm{PF}}$ (squares). L. castaneus and $L$. 674 eiseni individuals (open squares) are included. Two L. rubellus lineages are apparent, 675 termed lineage 'A' (light grey) and 'B' (dark grey), respectively, with a mean inter676 lineage mtDNA sequence divergence of approximately 13\%. Tree topology was well 677 supported by bootstrap analyses. Only one representative of each haplotype at the 678 particular sites and are shown; numbers in parentheses indicate the numbers of 679 individuals of a given haplotype. 